\title{
IMPLEMENTATION OF BLENDED LEARNING IN ENGLISH AS A LINGUA FRANCA (ELF)-AWARE PRE-SERVICE TEACHER EDUCATION
}

\author{
Dr. Elif KEMALOGLU ER \\ ORCID: 0000-0003-1238-1018 \\ Department of Translation and Interpreting \\ Adana Alparslan Turkes Science and Technology University \\ Adana, TURKEY \\ Dr. Yasemin BAYYURT \\ ORCID: 0000-0002-3851-0888 \\ Department of Foreign Language Education \\ Bogazici University \\ Istanbul, TURKEY
}

Received: 12/02/2021 Accepted: 27/04/2021

\begin{abstract}
Blended learning which synthesizes face-to-face instruction with distance education opportunities in educationally meaningful ways aims to take advantage of the affordances of both genuine and virtual types of teaching and ubiquitously equip learners without the limitation of time and space. Blended learning has been integrated into several pre-service teacher education courses to soundly cultivate teacher candidates with the efficient use of online and class time. Yet, to date, there has been no research on the use of blended learning in English as a lingua franca (ELF)-aware pre-service teacher education. This study aims to introduce an intensive blended learning model devised to raise ELF-awareness of pre-service teachers via critical reflection and investigate its effectiveness through their views. The data were collected by a questionnaire with closedand open-ended items and semi-structured interviews and analyzed via quantitative and qualitative analysis. The findings showed the blended learning model was rated to be effective in raising ELF-awareness of the participants. The advantages of the model were also reported along with challenges and the ways to address them. Overall, the results indicate a high level of satisfaction about the model and it is suggested blended learning be used in pre-service teacher education contexts.
\end{abstract}

Keywords: Blended learning, ELF-aware pre-service teacher education, face-to-face education, distance education, online learning, pre-service teacher education.

\section{INTRODUCTION}

Blended learning is an instructional method which combines face-to-face instruction given during class time with online education provided out of class time using synchronous and/or asynchronous digital technologies. As the combination of face-to-face and online learning, it aims to avoid the pitfalls of purely technology-based instruction and effectively maximize the benefits of both to reach feasible outcomes (Bersin, 2004; Garrison \& Kanuka, 2004; Stein \& Graham, 2014). In a typical blended learning model, face-to-face instruction performed in the classroom context is the main component of teaching and digital learning tools are used to reinforce and deepen learning (Ferdig, Cavanaugh \& Freidhoff, 2012). With virtual learning possibilities, it enables learners to receive ubiquitous education, which enhances the flexibility and worldwide accessibility of teaching and learning (Stein \& Graham, 2014). Blended learning models are also maintained to support students to become lifelong learners with the ability to learn continuously outside the class and manage their own learning process (Karatas, 2017; Parisi, Kemker, Part, Kanan \& Wermter, 2019). Blended learning is also said to provide an extensive learning experience since it not only provides 
an enriched context with the combination of face-to-face and distance education but also enables learners to acquire and improve both content and technological knowledge and help them advance in technological literacy (Cleveland-Innes \& Wilton, 2018).

Blended learning has been gaining momentum in higher education (e.g. Alammary, Carbone \& Sheard, 2016; Bayyurt \& Kerestecioglu, 2018; Castro, 2019) and it is also crucial to incorporate blended learning in pre-service teacher education as it can make it possible for prospective teachers to gain knowledge and experience in educational technology and help to bridge the gap between rapid progress in technologyenhanced instruction and teacher competencies via taking advantage of both online and in-class aspects blended in an overarching instruction (Atmacasoy \& Aksu, 2018). Moreover, as emphasized by Mishra \& Koehler (2006), integration of blended learning in pre-service teacher education comprises the development of three distinct, but overlapping types of knowledge: content, pedagogical, and technological knowledge. According to Scarlett (2017), through blended learning, student-teachers can engage with the technology rather than passively learn about the technology, thus they can form and improve the technological knowledge base essential for successful teaching with technology. As mentioned by Kennedy \& Archambault (2012), it is significant to equip future teachers to teach in multiple formats in both online and traditional contexts, and guide them about the ways to effectively harmonize them. Moreover, O'Byrne \& Pytash (2015) suggest teachers should experience blended learning for themselves in their own professional development to best internalize the tenets and practice. Blended learning has been applied and investigated in several pre-service teacher education courses. To illustrate, in Senturk (2020), which aimed to investigate the effects of a blended learning approach on academic achievement and twenty-first century skills of pre-service teachers via a semi-experimental research design, the model proved to be effective with a significant difference in favor of the experimental group. Similarly in their quasi-experimental study, Monicka \& Jayachithra (2018) found that blended learning significantly increased the teaching competency of the teacher candidates. In Caner (2010), a blended learning model integrated into a teaching practice course resulted in the general satisfaction of pre-service teachers and it was concluded that blended teaching practice courses can enhance interaction, strengthen peer collaboration, and establish a sense of community. Shand \& Farrelly (2017) used blended learning to teach blended learning in a methodology course and found that the learners found the course effective on the basis of clear lesson objectives, well-defined assignment directions, availability of relevant resources and continuous discussion on personal, professional, and academic issues. In Scarlett (2017), most participants thought the blended learning model they employed increased their comfort level with educational technology, improved their ability to work with it and gave them more flexibility in their schedule. In Yilmaz \& Malone (2020), student-teachers' perceptions were positive towards the use of blended learning, yet they had some concerns about technological hindrances. As stated in the review of Atmacasoy \& Aksu (2018) on 31 studies on blended learning in pre-service teacher education, a majority of studies verified the effect the model had on achieving course outcomes. The pre-service teachers had positive attitudes towards the courses' being blended and it was face-to-face part of the course that was liked best as it boosted social interaction among stakeholders. Blended learning model was also favored due to variability of materials, accessibility to instant feedback and following up student progress. On the other hand, blended learning was said to involve some barriers such as slow internet access and connection problems. It was suggested it would be feasible to design courses in hybrid modes rather than as isolated online courses due to the benefits blended learning presents.

Despite different experimentations of blended learning tested in pre-service teacher education literature, there have been no attempts to include and investigate blended learning in English as a Lingua Franca (ELF)-aware pre-service teacher education. ELF is a paradigm in English language teaching (ELT) which acknowledges non-native varieties in their own right rather than assess them against a native speaker benchmark (Jenkins, Cogo \& Dewey, 2011). Aiming to raise pre-service teachers' awareness of ELF and challenge their deeply-seated convictions about the superiority of native speakers, the ELF-aware pre-service teacher education model in this study focuses on raising consciousness of the variability of English use in today's globalized world, acknowledgement of non-native speakers with their own unique characteristics, and applying an egalitarian and humanitarian pedagogical approach that embraces all users of English (Kemaloglu-Er \& Bayyurt, 2016, 2018, 2019, 2020). The model reveals an adaptation of the ELF-aware teacher education model devised and improved by Bayyurt \& Sifakis (2015a, 2015b; 2017), Sifakis (2014, $2019)$ and Sifakis \& Bayyurt $(2015,2018)$ for in-service English language teachers. The essential feature 
of "ELF-aware teacher education" is that it aims at the critical reorientation of the teachers' deeper beliefs and convictions about English language and English language teaching/learning and communication in a global language. According to Bayyurt \& Sifakis (2015a, 2015b), English teachers may be aware of the global function of English as well as some of its consequences, yet they may still be in confusion with regard to the incorporation of ELF into ELT pedagogy and their own teaching context. Thus, if the aim is full appreciation of research in ELF, it is necessary that they internalize this research by critical reflection on ELF in theory and practice so that their long-held and deeply-rooted viewpoints about native speakerism can be challenged. In this framework, English teachers get deeply involved with the concept of ELF and relate it to their own teaching through critical reflection and reflective interactions. The model of ELF-aware inservice teacher education (also abbreviated as ELF-TEd) that served as an initial sample for the current ELFaware pre-service education model in this study was carried out with participant-teachers from Turkey and Greece. Its aim was to make EFL teachers aware of several issues on ELF and ELF-aware pedagogy through reading and critical reflection on current literature on ELF as a sociolinguistic concept and a pedagogical perspective, followed by teaching experience that involves integrating teachers' understanding of ELF into their classroom practice as well as their evaluation of this experience (Bayyurt \& Sifakis, 2015a, 2015b; 2017; Sifakis, 2014, 2019; Sifakis \& Bayyurt, 2015; 2018). Such awareness was intended to challenge the teachers' convictions and practices in their mindsets about several ELF-related issues including Standard English, the roles of native and non-native speakers, mutual intelligibility in communication with nonnative speakers as well as their roles as correctors and feedback providers in the classroom. The ELF-TEd project extensively took place in the form of both distance learning via a website designed as an online learning portal specifically developed for the training with uploaded readings, videos and relevant questions as well as face-to-face meetings with the participant teachers. The training was conducted in three distinct phases: theory, application and evaluation. In the theory phase, the participants were expected to read the ELF-related readings and watch the given videos and respond to the reflection questions provided via the portal. In the application phase, the teachers developed and taught ELF-aware lesson plans for their own classes. In the evaluation phase, the participants engaged in a self and/or peer-evaluation of their lessons or activities. In these phases they were asked to upload their lesson plans and assessments on the portal. Hence, a great deal of work was performed through an online portal in the form of distance learning, but there were also biweekly face-to-face meetings held in Istanbul, Turkey to interact about the ELF-related issues, give morale support to the participants and answer any kind of training- or technology-related questions. While the instructor and the participants in Turkey were having these face-to-face meetings, the stakeholders in Greece attended the meetings through Skype. Although it was not referred to as a blended learning model at the time, it was a version of the implementation of a blended learning approach to in-service teacher education. Thus the ELF-aware in-service teacher education model taken as basis in this study was actually a blended form of training as it had both an online learning portal with ELF-related readings, videos and question-answer sections as well as fortnightly face-to-face meetings.

As for the ELF-aware pre-service teacher education model of this study, the model described above applied with in-service teachers has been adapted to a pre-service teacher education setting at an English-medium state university in an elective course offered by one of the authors of this paper. For this purpose, the original model was modified and intensified with intensive critical reflections, reflective interactions, practice-related patterns and technological enhancement. The pre-service education also had theoretical and practice-related phases as in the in-service version, but this time there were face-to-face in-class sessions held every week as a part of the course where the student-teachers discussed the assigned ELF-related topics and these in-class sessions were tactfully synthesized with the online components of the course designed for distance education. The participant-teachers accessed the weekly readings and/or videos and answered the reflection questions via their online platform as in the in-service version of such education, but different from the in-service framework, they also had online discussions every week about the given readings and/or videos and related topics. Hence, compared to the in-service model, reflective interactions were an emphasized component of the ELF-aware pre-service teacher education model and they were practiced in a blended way, i.e. both face to face and online. Moreover, a mobile learning component was integrated into the model to take advantage of the young adult teachers' continuous interest in mobile actions and make their ELF-related learning experience ubiquitous and effective. To help the student-teachers deal with the theory building process marked with intensive amounts of readings, videos, reflection and discussion, mobile learning was 
used as a supportive means for both content guidance and class interaction. That is, parallel to the readings, each week, the teachers received quotes selected from the given readings and/or videos through a mobile communication platform and communicated about the received content.

The blended learning model was developed in order to enable teacher candidates with little or no knowledge and experience related to ELF and its pedagogy to gain a sound and multifaceted ELF-aware perspective and make them ready to practice it in contextualized ways. It was deemed that by exposing them to a program with intensive readings, critical reflections, and reflective interactions making use of not only faceto-face but also virtual opportunities extending beyond the classroom, the teachers could be well-equipped making the most of the training time. That is why a blended learning model with multidimensional learning opportunities was chosen and designed. To this end, the current blending learning model designed and implemented in the present study integrated i) a website designed as an online learning portal with ELFrelated readings, videos and relevant reflection questions to be replied by the student-teachers, ii) an online discussion platform where the key aspects of each given reading and/or video were regularly discussed, iii) a mobile learning component through which the significant quotes from the given readings and/or videos were systematically sent to the prospective teachers mobile phones as messages and discussed, and iv) faceto-face teaching and discussion sessions conducted each week to collaboratively and reflectively interact about the given ELF-related issues, as elaborated below. This study aims to investigate the effectiveness of this ELF-aware blended learning model in raising ELF-awareness of the participants and analyze the relevant benefits and challenges as well as the ways to deal with challenges by exploring the opinions of the participants about the model and its components.

\section{METHOD}

\section{Setting}

The present study takes place in the Department of Foreign Language Education at an English-medium state university in Istanbul, Turkey within the four-year undergraduate program for pre-service English language teachers, at the end of which the students receive a Bachelor of Arts (BA) degree in English language teaching. The curriculum of this program is monitored and inspected by Turkish Higher Education Council as in other pre-service English language teacher education programs in the country. Basically, the pre-service teacher education program comprises courses aiming at teacher candidates' English language and professional development. During the course of the program, each semester, students are expected to take 5 to 7 courses. There are three major phases of the program. The first phase involves English language development of the teacher candidates (e.g., academic writing or public speaking), the second phase aims at theoretical training (e.g., survey of applied linguistics, second language learning theories, sociolinguistics and education), and the final phase focuses on the practical aspects of English language teaching (e.g., foreign language teaching methods, skills teaching, practicum).

The elective course entitled "English as a Lingua Franca (ELF)-Aware Teacher Education" was offered to senior year students in a blended learning format in the last year of their BA program. At the time of data collection, this course was offered in the program adapting a blended learning format for the first time. The first part of this ELF-aware education course focused on theory building, critical reflection and discussions on the issues concerning ELF-awareness-related literature and its pedagogical implementations while the second part was based on the integration of an ELF-aware approach into the teaching practice and critical reflection on this practice.

\section{Blended Learning Model}

The aim of this study is to design, apply and investigate a novel, intensive and critical reflection-focused ELF-related pre-service teacher education course adopting a blended learning approach. The contents of the course are designed in such a way that they aim to challenge pre-service teachers' deeply-seated convictions about English language related issues like native speakerism, ownership of English, accented language use and similar. The course also targets at raising pre-service teachers' awareness of ELF both as a sociolinguistic concept and a pedagogical perspective acknowledging non-native speakers with their own 
unique backgrounds and characteristics. For such a possible change to happen, it was decided prospective teachers should be provided with an intensive course syllabus rich in theory and practice including readings, videos, critical reflections and reflective interactions. In order to handle this intensive curriculum, it was essential to have the teacher candidates use their in-class and out-of-class time efficiently, thus a hybrid form of educational model taking advantage of not only face-to-face education but also distance learning performed with a variety of technologically-enhanced means was designed and implemented. The model included an online learning portal specifically designed for ELF-aware teacher education, online discussions and a mobile learning component.

The course is a departmental elective course in the program and was officially instructed by the second author of this article. The instruction in the blended learning format was implemented for one academic semester (14 weeks) within the "English as a Lingua Franca (ELF)-Aware Teacher Education" course given for the second time in the department. In the first two weeks, the participants were introduced to the course and given training about how blended learning would be applied and what they were required to do as students. Then the 12-week ELF-aware blended training period started. The blended learning model was applied as a combination of weekly face-to-face instruction sessions with distance learning implemented with online learning tools (an online learning portal, online discussions and a mobile learning component) as elaborated below.

\section{Theoretical Phase}

\section{Face-to-face Meetings}

The class had in-class face-to-face meetings each week. In those meetings the readings/videos of the week were discussed and the technical questions related to the online learning portal, if any, were also answered. Moreover, oral feedback about weekly assignments was provided. Attendance to those meetings was announced to be compulsory and participation in the discussions was also announced to have an effect on the student-teachers' grades. There were fourteen in-class meetings in total held with the group. The meetings were arranged as three 45 -minute sessions per week.

\section{Online Learning Portal}

The online learning portal included ELF-related readings, videos and reflection questions for the theoretical training and a section to upload the practice-related tasks. In the theoretical phase, the pre-service teachers were required to regularly read the given ELF-related articles and book chapters and watch relevant videos where the concerning issue was explained by the experts and answer the relevant reflection questions related to the readings and videos on the online learning portal on a weekly basis. Each reading or video was presented with the reflection question/s attached which helped the participants to summarize the main points in the readings/videos and/or compare them with the points in the previous readings and/or videos. The student-teachers were also asked to present not only their personal opinions on the given issues but also the relevance of the issues to their teaching context. During the whole term, they were asked to read 25 ELF-related articles and book chapters and watch 10 videos including interviews with ELF scholars and their plenary speeches and leading educational experts' TED-talks. They were also expected to give responses to 37 reflection questions following the given readings and videos. The participants also prepared and uploaded practice-related tasks on the portal and they received written feedback about their responses and tasks from their instructors.

\section{Online Discussions}

Online discussions were added to the model in order that the viewpoints of the participants could be enriched through reflective interactions ubiquitously applied in the participants' own settings. Each week the class was sent prompts related to the readings/videos of the week through Google groups. In order to sustain participation, it was announced that each participant was expected to post at least one comment about the prompt and one comment about his/her classmate's response. The students were also informed about the fact that responses would be graded. The discussion prompts complemented the given readings and reflection 
questions and they all aimed to make the student-teachers reflect on the pertinent ELF related issue and connect it to their teaching context. There were 12 online discussions in total held about the readings and/ or videos of the weeks during which the ELF-aware pre-service teacher education course was implemented.

\section{Mobile Learning Component}

In this model, mobile learning was also utilized as a vehicle to help the participants follow up the main contents of the assigned readings/videos, effectively respond to the reflection and discussion questions and increase their motivation about the course. That is, in line with the given readings, each week, the studentteachers received quotes selected from the given readings through a mobile communication platform, which is WhatsApp in our case. In selecting the quotes, the ones that would make the student-teachers ponder the points of the articles relevant to the assigned reflection questions and help them recall the essence of readings were chosen. This mobile learning application was named "Quote Reminders and Thought Provokers". Each quote was numbered and sent with the surname of the author and the year of publication. They were sent at the weekends as it was expected that the participant-teachers would then work on their readings, papers and discussions extensively. There were 5-7 quotes sent each weekend. The teachers also posted their immediate comments on the sent quotes and discussed the issues and/or interacted on the course content or requirements on WhatsApp.

In designing the blended learning model, the researchers looked for high quality, convenient and economical online means for effective and sustainable technology-enhanced education. For this purpose, they used the online learning portal designed specifically for ELF-aware teacher education purposes and already tested with previous ELF-aware trainings given to in-service teachers - i.e., the ELF-TEd project. For online discussion purposes they chose Google groups and for mobile learning and communication they opted for WhatsApp as commonly used and updated platforms that were free of charge.

\section{Practice-related Phase}

For the second phase of the course focusing on the practice-oriented aspects of ELF-aware teaching, blended learning was implemented as the combination of practice-related tasks prepared by the participants and uploaded on the online learning portal and feedback given to them on a weekly basis. The pre-service teachers in the research setting were supposed to actively teach in their practicum classes in the second term after observing these classes in the first term and since the course was given in the first term, in the practicerelated part of the course, the pre-service teachers could not be asked to do ELF-aware teaching practice, thus they were asked to make ELF-related preparations for their future teaching practices. In this phase, first the participant-teachers were asked to reflect on and write about their ELF-related autobiographies. In these autobiographies, they were expected to write about their own backgrounds as a learner and a prospective teacher of English highlighting the educational aspects in their lives related to ELF-aware pedagogy. Following this retrospective analysis, they were asked to design an imaginary ELF-aware lesson plan for the practicum class they were supposed to be observing for the whole term and write their reflections about the possible advantages and challenges of the plan as well as the ways to deal with the described challenges and upload their lesson plans and reflections on the portal. The autobiographies and lesson plan assignments were provided with oral and written feedback.

\section{Assessment}

The student-teachers' performance in the course was assessed on the basis of their answering the reflection questions on the portal, their lesson plans and related reflections as well as their participation and performance in face-to-face meetings and online-discussions. Each component was given points, the performance of the participants in those components were formatively assessed according to the defined rubrics, and these component-based points were summed up for a total grade. It was also thought that the student-teachers might not participate in all face-to-face meetings and online discussions due to personal reasons, thus nonattendance was allowed in thirty percent of the total number of these meetings. Hence the participation grades were calculated on the basis of attendance in seventy percent of these gatherings. 


\section{Participants}

12 pre-service teachers participated in the study. 6 of them were female and 6 male. Their ages varied between 22 and 24 . All of them were senior students. As they said this was their first blended learning experience during their undergraduate studies. The research was conducted with all the participants who attended the entire education course from the beginning to the end. All of them were informed about the study, voluntarily participated in the research and signed consent forms. Those students, who did not sign consent forms, dropped the course and enrolled to another course. As mentioned earlier, this course was an elective course and the students voluntarily selected it.

\section{Data Collection}

The data were collected via a questionnaire with closed- and open-ended items and semi-structured interviews. In the closed-ended items of the questionnaire, the participants were asked to score the effectiveness of the blended learning model and each component within the model in raising the participants' ELF-awareness on a three-point scale as 1- Not effective 2- Effective and 3-Very effective. In the open-ended part of the questionnaire, the respondents were asked to state the advantages and challenges of the blended learning model as well as each component within the model and the ways to deal with the challenges. The semistructured interviews conducted with each participant also focused on the benefits, challenges and proposed solutions to elicit in-depth data.

\section{Data Analysis}

Both quantitative and qualitative analysis were employed in this study. The data of the closed-ended items of the questionnaire were quantitatively analyzed and frequencies of the responses to each questionnaire item were calculated and turned into percentages. Open-ended questionnaire items and semi-structured interviews were qualitatively analyzed via thematic analysis. For this purpose, salient and recurring themes and patterns were identified and categorized by moving back and forth within the data through multiple readings and iterative analyses (Creswell, 2013). The main themes, namely, the benefits, challenges and proposed solutions regarding the model and its components, as well as the sub-themes under each main theme were analyzed and defined according to the data gathered through pre-service teachers' responses.

\section{FINDINGS}

\section{Effectiveness of the Model and Its Components}

The effectiveness of the model in raising pre-service teachers' ELF-awareness was investigated via the closedended items in the questionnaire. The responses to the closed-ended items in the questionnaire about the effectiveness of the blended learning model and its components in raising ELF-awareness of the participants varied between "effective" and "very effective" and a small percentage of the participants scored some components as "not effective". Table 1 shows the rates of responses about the effectiveness of the model and its components in percentages.

Table 1. Effectiveness of the model and its components rated by the participants

\begin{tabular}{lccc}
\hline & Not effective (\%) & Effective (\%) & Very Effective (\%) \\
\hline Blended learning model & 0 & 55.2 & 44.8 \\
Face-to-face meetings & 0 & 31.1 & 68.9 \\
Online learning portal & 0 & 62 & 38 \\
Online discussions & 10.3 & 80.7 & 9 \\
Mobile learning component & 6.8 & 77.7 & 15.5 \\
\hline
\end{tabular}


As shown in Table 1, the responses about the blended learning model varied between "effective" and "very effective" and over half of the participants (55.2\%) rated the model to be "effective" while $44.8 \%$ rated it to be "very effective". Face-to-face meetings were rated to be a "very effective" component of the blended learning model by a majority of participants $(68.9 \%)$ and it was the item with the highest response rate among the items perceived to be "very effective". Online learning portal was found to be "effective" by a majority of the participants (62\%), followed by "very effective" (38\%). Among the components, it was online discussions and mobile learning component perceived to be "not effective" by a small percentage of the participants (10.3\% and $6.8 \%$ respectively). On the other hand, online discussions and mobile learning were rated to be "effective" parts of the blended learning model by the majority of the respondents ( 80.7 and $77.7 \%$ ). Lastly, online discussions were perceived to be "very effective" by $9 \%$ of the participant-teachers while mobile learning was rated to be "very effective" by $15.5 \%$ of them.

\section{Benefits}

The open-ended questions in the questionnaire and interviews with pre-service teachers revealed several benefits of blended learning and its components on student-teachers' awareness of ELF and its possible implementation in their English language classrooms. The benefits of the implementation of a blended learning model involved being exposed to learning both within and outside the classroom and taking advantage of the benefits of not only traditional face-to-face learning but also distance learning. That is, a great majority of the respondents stated that they experienced both active genuine sharing in the classroom atmosphere through face-to-face interactions and distance learning opportunities free of time and space and this hybrid form of experience enabled them to learn about ELF and ELF-aware pedagogy in a multifaceted format. This enriched form of the model was found to be a favored aspect of the model by a great majority of the participants. Below are some sample excerpts that display this satisfaction:

This is the first blended experience which we've had for the first time. I think we have lived it to the fullest. All these face-to-face and digital opportunities have enabled me to extend my knowledge and experience on ELF.

It was a lively experience where we were really active and productive. I was able to increase and share my accumulation on various topics without the limitations of time and space.

The perceived advantages of the components of the model were also analyzed as mentioned below.

\section{Face-to-face Meetings}

One of the most frequently mentioned benefits of the face-to-face meetings was that these meetings created a genuine and sincere atmosphere in the classroom that made the participants express their opinions and emotions more easily and the exchanges of opinions and feelings more fluent. Another commonly stated advantage was their contribution to an increase in motivation to learn about ELF and its components due to active, dynamic and reflective interactions that took place between the students during the face-to-face class sessions. It was also stated by some participants that face-to-face meetings was the unique component of the course governed with real-life oral interactions and such interactions were more enjoyable compared to all the other interactions in the model which were in written form. Thus face to-face meetings' being in oral form was a favored part of the model as it was said to help the participants express themselves in a more active, genuine and fluent way.

\section{Online Learning Portal}

The portal specifically prepared for the course was stated to give the participants a sense of importance as well as a sense of belonging. The participants stated that the online learning portal increased their motivation to learn new constructs and concepts that were related to their profession. The portal was also stated to provide a useful archive of ELF-related readings and reflection questions accessible anywhere anytime. The readings and videos within the portal were pointed out to be useful in understanding ELF and relevant concepts in a 
gradual manner from the general to the more specific. The reflection questions provided to the respondents after each reading and/or video were deemed to highlight the key issues of the readings and videos and relate them to the participants' own knowledge and experience. The portal's theoretical part with readings and reflection questions and practice-related part with sections to upload participants' autobiographies and lesson plans were also considered to provide a useful format soundly guiding the participants in their theoretical and practice-related experience with ELF-awareness.

\section{Online Discussions}

In general, online discussions were defined as beneficial and complementary components of blended learning. They were stated to form a harmony between face-to-face discussions and enrich the ELF-related views of the participants. Since the discussions were in written form and in the format of threads, they could be seen as a whole with each participant's comments so this enabled the participants to follow up the flow of discussions in coherence. They were also defined to effectively help the participants understand the given readings and guide the responses to reflection questions as they were practiced as assignments at the same time with assigned readings and reflection questions of the week.

\section{Mobile Learning Component}

Receiving quotes from the assigned readings through a mobile communication platform at certain intervals every week was defined to be both informative and motivating by most participants. Several of them said that the quotes they received increased their curiosity to learn, directed them to the readings and helped them focus on the key issues of the readings. The mobile discussions that took place following quote reminders were also said to help the participant-teachers gain new insights in ELF-related issues. They also aided the participants to keep up with what was going on in the course. An additional advantage was that they gave the student-teachers the opportunity to revise the basic course content regardless of time and place. It was also stated that the mobile learning component made the participants feel important and gave them a sense of belonging and community.

\section{Challenges and Suggestions}

For the blended learning model, the thematic analyses of open-ended questionnaire items and semistructured interviews resulted in mainly two challenges: ubiquity and heavy workload.

\section{Ubiquity}

Through blended learning, the participant-teachers had the chance to receive ELF-aware education not only in the classroom via face-to-face meetings but also beyond the four walls of the classroom through a multifaceted form of online learning. However, being accessible and being exposed to ELF-related training anytime and anywhere was deemed to be not only an advantage but also a challenge by a great majority of participants since this was thought to be exhausting and intervening with private life. Some pre-service teachers pointed out it was hard to deal with the upcoming online assignments, online discussions and mobile phone messages at the same time and this caused anxiety and sometimes demotivation. Another mentioned point was that during the first weeks, mobile messages were sent early in the morning at weekends and this caused discomfort and annoyance and then the researchers and the participants decided that all forms of online communication within the course would be done between certain times, i.e. between ten am and seven pm so as not to disturb the participants.

\section{Heavy Workload}

Every week the participants were assigned ELF-related readings and videos and asked to answer the related reflection questions and actively participate in not only face-to-face but also online discussions. The teachers were also demanded to follow their mobile phone messages in the form of quotes from the weekly readings and videos. They were also asked to take part in and follow the related mobile communications. 
This multivariate blended learning model, thus, was considered to cause heavy workload by a majority of teachers. The following excerpt exemplifies such challenges of the model expressed by the participants:

We were already busy with the curricular duties of the program as senior students and the course overall was very demanding as we were wholly surrounded by readings, discussions and heavy tasks. (...) The course was useful but being accessible all the time and being continuously occupied with online tasks was really tiring.

As for suggestions to deal with these challenges, it was suggested that heavy workload and the demands brought about by the ubiquity of online learning could be overcome by revising the existing course load by for instance reducing the number of readings and relevant tasks and/or extending the course to two terms as two consecutive courses.

Regarding the components of the blended learning model, there were few challenges mentioned together with suggested solutions:

\section{Face-to-face Meetings}

There was not an emphasized challenge specific to face-to-face meetings, yet one verbalized challenge of face-to-face meetings in this blended learning model was that sometimes the course time was devoted to answering participants' technical questions and listening to their complaints about the course load rather than discussions about the readings and in those cases some participants thought they could not use in-class time efficiently for academic improvement. It was recommended that these issues can be dealt in the breaks or in office hours, not within class time.

\section{Online Discussions}

Online discussions were overall perceived to be useful but one challenge mentioned by some participants was that some themes in the online discussions were perceived to be repetitive of what had already been mentioned in face-to-face discussions, reflections done within the online learning portal and mobile interactions. Thus it was suggested that the discussion prompts should be given in such a way that they should lead to variability and/or enrich the themes already handled in other blended learning modules.

\section{Mobile Learning Component}

Some participants stated that it was hard for them to follow the long threads so the information sent through the mobile platform should be limited and there should be space between each reading reminder group. Also as they said, the unification of quote reminders and mobile interactions within one mobile platform led to confusion and distraction of attention in following the quotes and mobile interactions. Thus it was suggested the classroom interaction group and the quote reminder group be arranged as separate entities.

\section{DISCUSSION AND CONCLUSION}

Blended learning model designed and applied in this study has overall been rated to be an "effective" system in raising ELF-awareness by almost half of the participants and a "very effective" one by the other half. The components of the model have also been defined to be "effective" or "very effective" by a great majority of participants. These quantitative findings together with the qualitative ones emphasizing the advantages of the model display that the blended learning model within this ELF-aware pre-service teacher education course has been deemed to be beneficial with the use of not only face-to-face education but also distance learning with variate online components intended to be reflective and interactive.

As revealed by the data, the pre-service teachers pointed out several advantages of face-to-face and online components. Face-to-face meetings where the participants shared the same in-class setting were said to lead to genuine, dynamic and reflective oral interactions with a fluent flow. Among the online components, the online learning portal with readings, videos, reflection questions and practice-related sections were stated to help raise ELF-awareness of the teacher candidates with its intensive and ubiquitous content. Online 
discussions regularly held each week about the assigned readings complemented face-to-face discussions, helped the participant-teachers better understand the content of the readings and do the reading-related tasks in an effective way. The mobile learning component, through which the participants regularly received selected quotes from the assigned readings on their mobile phones and interacted about the meanings of them, was also perceived to be an illuminating and motivating means reminding them of the readings of the week and triggering reflective thinking beyond the classroom.

On the other hand, this ubiquitous form of learning with variability of online sources was found to be a commonly mentioned challenge as it was said to cause confusion between the divisions of academic and private life as well as exhaustion. Overall, the course load was found to be heavy and having to be accessible and active outside the classroom was stated to be demanding. Thus it was suggested that the course content could be reduced and extended to two terms. Despite the challenges, the satisfaction level of the participants about the blended learning model appears to be high as shown by the high ratings regarding the effectiveness of the model and its components and the advantages emphasized by the great majority outnumbering challenges. The findings of the study are therefore in line with several of the other blended learning studies on pre-service teacher education (Atmacasoy \& Aksu, 2018; Caner, 2010; Monicka \& Jayachithra, 2018; Scarlett, 2017; Senturk, 2020; Shand \& Farrelly, 2017) as they in general show that blended learning has been perceived to be effective and resulted in participants' general satisfaction with variability of learning modes, materials and tasks accessible regardless of time and place and perpetual discussions on academic, professional and personal issues. Moreover, similar to those studies, in this study, blended learning has also displayed some hindrances. Yet, in this study, the challenges were not centered on technology and/or internet-related problems as is the common case in the other studies, but it was intensive course content as well as being accessible anytime and anywhere through online means found to be exhausting. Another difference is that in the aforesaid blended pre-service teacher education models, the online learning means did not include a mobile learning and interaction component. The mobile component of the model in this study was rated to be "effective" or "very effective" by most of the participants and found to enhance participation and motivation, remind the teachers of their weekly tasks and prompt them to think and voice their thoughts about the topic. Also according to the findings, mobile learning made the participantteachers feel important and helped to form a sense of community and belonging. Thus in this study, the integration of mobile learning into the blended learning model has led to a high level of satisfaction among the participants. Besides, not only mobile learning but also all the other components, namely the online learning portal, online discussions, and face-to-face meetings were all thought to be useful means orienting and supporting the ELF-related improvement of the participants and the ratings about the effectiveness of the overall blended learning model along with its components have all been high.

The findings thus imply that blended learning can be an effective means to be used in pre-service teacher education as well as ELF-aware pre-service teacher education. It has been the first time blended learning has been applied and researched as a model within ELF-aware pre-service teacher education and this study has shown that it has been deemed as an effective model in raising ELF-awareness of prospective teachers. Future studies may focus on the incorporation of this blended learning model into ELF-aware and/or other types of pre-service teacher education courses and investigate its effectiveness.

Besides, the Covid-19 pandemic crisis has shown the whole world the importance of distance education, a useful means to receive education free of time and space specifically in emergency situations. On the other hand, the distance education experience in the Covid-19 period has also highlighted the fact that a distance educationonly pedagogy can have drawbacks such as lack of face-to-face interaction and physical touch and accordingly lack of emotional engagement in interpersonal interactions, decrease in focus and attention, deterioration of course and classroom management, decline in motivation, health-related problems stemming from too much exposure to screen as well as technical problems (e.g. Atmojo \& Nugroho, 2020; Karatas \& Tuncer, 2020; Korkmaz \& Toraman, 2020; Octoberlina \& Muslimin, 2020). This implies a need for face-to-face education, a genuine and potentially lively resource that can compensate the deficiencies of online learning.

This study has aimed to be a significant contribution to the field of ELT, highlighting two vital aspects necessary for 21st century pre-service English language teacher education: ELF-awareness and effective use of technology in education and it has shown that blended learning can be harmonized with ELF-awareness in pre-service teacher education and such a synthesis assumes the potential to achieve effective outcomes. 


\section{BIODATA and CONTACT ADDRESSES of AUTHORS}

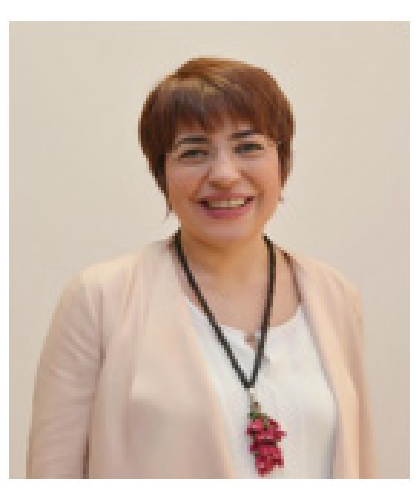

Dr. Elif KEMALOGLU ER is Assistant Professor in the Department of Translation and Interpreting at Adana Alparslan Turkes Science and Technology University. She received her BA degree from Translation Studies at Bogazici University. She completed her MA in Teaching English as a Foreign Language at Bilkent University and she earned her PhD degree in English Language Education at Bogazici University. She has extensive English language teaching experience at reputable institutions in Turkey. Several of her publications focus on English as a lingua franca (ELF)-awareness in language teaching and teacher education and she has been an active participant and a leader in multifaceted ELF-related projects. Her research interests include English language teaching, ELF and Global Englishes, and technology-enhanced learning.

\section{Elif KEMALOGLU ER}

Department of Translation and Interpreting, Faculty of Humanities and Social Sciences

Address: Adana Alparslan Turkes Science and Technology University, 01250 Saricam, Adana, Turkey

Phone: +903224550000 / 2621

E-mail: ekemalogluer@atu.edu.tr

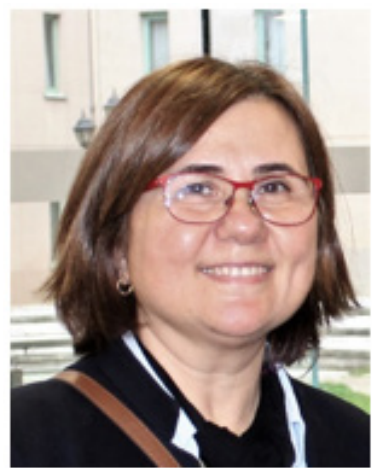

Dr. Yasemin BAYYURT is Professor of Applied Linguistics at Bogazici University, Istanbul, Turkey. She holds a PhD degree in English Linguistics from Lancaster University, UK. Her current research on English and English language teaching/learning focuses on ELF-aware pre-/in-service teacher education; ELFawareness in English language teaching/learning; EMI in higher education; and CLIL in K12 schools. She also carries out research on the impact of blended/mobile/distance learning on students' academic performance in higher education programs (engineering, medicine, English language education ...). Her publications include articles in various indexed journals (World Englishes, Language Culture and Curriculum, Journal of English for Academic Purposes...); edited books and book chapters published by national/international publishers. She co-edited "Mobile as a Mainstream - Towards Future Challenges in Mobile Learning" (2014), published by Springer; co-edited "Current Perspectives on Pedagogy for English as a Lingua Franca" (2015), published by De Gruyter; and edited one of the volumes of Bloomsbury World Englishes series entitled "Bloomsbury World Englishes Volume 3: Pedagogies" (2021), published by Bloomsbury.

\section{Yasemin BAYYURT}

Department of Foreign Language Education, Faculty of Education

Address: Bogazici University, 34342 Bebek, Istanbul, Turkey

Phone: +90 $2123594558 / 6797$

E-mail: bayyurty@boun.edu.tr

\section{REFERENCES}

Alammary, A., Carbone, A. \& Sheard, J. (2016). Blended learning in higher education: Delivery methods selection. Research Papers, 150, https://aisel.aisnet.org/ecis2016_rp/150

Atmacasoy, A. \& Aksu, M. (2018). Blended learning at pre-service teacher education in Turkey: A systematic review. Education and Information Technologies, 23, 2399-2422. https://doi.org/ 10.1007/s10639018-9723-5

Atmojo, A. E. P. \& Nugroho, A. (2020). EFL classes must go online! Teaching activities and challenges during COVID-19 pandemic in Indonesia. Register Journal, 13(1), 49-76. https://doi.org/10.18326/rgt. v13i1.49-76 
Bayyurt, Y. \& Kerestecioglu, F. (2018). Effective use of online tools in engineering classes. In Palalas, A., Norman, H. \& Pawluk P. (Eds.), IIABL 2018 - Blended learning in the age of social change and innovation: Proceedings of the third world conference on blended learning (pp. 97-101). Athens: International Association for Blended Learning.

Bayyurt, Y. \& Sifakis, N. C. (2015a). Developing an ELF-aware pedagogy: Insights from a self-education programme. In P. Vettorel (Ed.), New frontiers in teaching and learning English (pp. 55-76). Cambridge: Cambridge Scholars Publishing.

Bayyurt, Y. \& Sifakis, N. C. (2015b). ELF-aware in-service teacher education: A transformative perspective. In H. Bowles \& A. Cogo (Eds.), International perspectives on teaching English as a lingua franca (pp. 117- 135). Basingstoke: Palgrave Macmillan.

Bayyurt, Y. \& Sifakis, N. C. (2017). Foundations of an EIL-aware teacher education. In A. Matsuda (Ed.), Preparing teachers to teach English as an international language (pp. 3-18). Bristol: Multilingual Matters.

Bersin, J. (2004). The blended learning book: Best practices, proven methodologies and lessons learned. San Francisco, CA: Pfeiffer.

Caner, M. (2010). A blended learning model for teaching practice course. Turkish Online Journal of Distance Education, 11(3), 79-97. Retrieved from https://dergipark.org.tr/tr/pub/tojde/ issue/16909/176358

Castro, R. (2019). Blended learning in higher education: Trends and capabilities. Education and Information Technologies, 24, 2523-2546. https://doi.org/10.1007/s10639-019-09886-3

Cleveland-Innes, M., \& Wilton, D. (2018). Guide to blended learning. Burnaby: Commonwealth of Learning.

Creswell, J. (2013). Qualitative inquiry and research design: Choosing among five approaches. Thousand Oaks: Sage.

Ferdig, R., Cavanaugh, C. \& Freidhoff, J. (2012). Lessons learned from blended programs: Experiences and recommendations from the field. Vienna: INACOL Publishing.

Garrison, D. R., \& Kanuka, H. (2004). Blended learning: Uncovering its transformative potential in higher education. Internet and Higher Education, 7, 95-105. Retrieved from https://www.sciencedirect. com/science/article/abs/pii/S1096751604000156?via\%3Dihub

Jenkins, J., Cogo, A. \& Dewey, M. (2011). Review of developments in research into English as a lingua franca. Language Teaching, 44(3), 281-315. https://doi.org/10.1017/S0261444811000115

Karatas, K. (2017). Predicting teacher candidates' self-directed learning in readiness levels for terms of metacognitive awareness levels. Hacettepe University Journal of Education, 32(2), 451-465. https:// doi.org/10.16986/HUJE.2016017218

Karatas, T. O. \& Tuncer, H. (2020). Sustaining language skills development of pre-service EFL teachers despite COVID-19 interruption: A case of emergency distance education. Sustainability, 12, 81 88. https://doi.org/10.3390/su12198188

Kemaloglu-Er, E., \& Bayyurt, Y. (2016). ELF-aware teacher education with pre-service teachers: A transformative and technology enhanced case from Turkey. In N. Tsantila, J. Mandalios \& M. Ilkos (Eds.), ELF: Pedagogical and interdisciplinary perspectives (pp. 261-267). Athens: Deree - The American College of Greece.

Kemaloglu-Er, E. \& Bayyurt, Y. (2018). ELF-aware pre-service teacher education: Teaching practices and reflections from Turkey. In L. Cavalheiro (Ed.), Preparing English language teachers for today's globalized world (pp. 47-63). Lisbon: Humus.

Kemaloglu-Er, E. \& Bayyurt, Y. (2019). ELF-awareness in teaching and teacher education: Explicit and implicit ways of integrating ELF into the English language classroom. In N. C. Sifakis \& N. Tsantila (Eds.), English as a Lingua Franca for EFL contexts (pp. 159-174). Bristol: Multilingual Matters.

Kemaloglu-Er, E. \& Bayyurt, Y. (2020). Project-based and ELF-aware pre-service teacher education in Turkey: Sample cases of discovery, creativity, interaction and multicultural diversity. In A. GrasVelazquez (Ed.), Project-based learning in second language acquisition: Building communities of practice in higher education (pp. 82-97). New York: Routledge. 
Kennedy, K. \& Archambault, L. (2012). Offering pre-service teachers field experiences in K-12 online learning: A national survey of teacher education programs. Journal of Teacher Education, 63(3), 185-200. http://dx.doi.org/10.1177/0022487111433651

Korkmaz, T. \& Toraman, C. (2020). Are we ready for post-COVID-19 educational practice? An investigation into what educators think to online learning. International Journal of Technology in Education and Science, (IJTES), 4(4), 293-309. https://doi.org/10.46328/ijtes.v4i4.110

Mishra, P. \& Koehler, M. (2006). Technological pedagogical content knowledge: A framework for teacher knowledge. Teachers College Record, 108(6), 1017-1054. Retrieved from http://one2oneheights. pbworks.com/f/MISHRA_PUNYA.pdf

Monicka, M. \& Jayachithra, J. (2018). Impact of blended learning in science teaching competency. Journal of Emerging Technologies and Innovative Research. 5(7), 144-146. Retrieved from https:// www.researchgate.net/publication/338065604_IMPACT_OF_BLENDED_LEARNING_IN_ SCIENCE_TEACHING_COMPETENCY

O’Byrne, W. I. \& Pytash, K. E. (2015). Hybrid and blended learning. Journal of Adolescent \& Adult Literacy, 59(2), 137-140. https://doi.org/10.1002/jaal.463

Octoberlina, L. R. \& Muslimin, A. I. (2020). EFL students perspective towards online learning barriers and alternatives using Moodle/Google classroom during Covid-19 pandemic. International Journal of Higher Education, 9(6), https://doi.org/10.5430/ijhe.v9n6p1

Parisi, G. I., Kemker, R., Part, J. L., Kanan, C., \& Wermter, S. (2019). Continual lifelong learning with neural networks: A review. Neural Networks, 113, 54-71. https://doi.org/10.1016/j.neunet.2019.01.012.

Scarlett, M. H. (2017). Blended learning in teacher education: A case study from a small, private college. Retrieved from

https://conference.iste.org/uploads/ISTE2017/HANDOUTS/KEY_108226560/BlendedLearningin TeacherEducation_ResearchPaper_ISTE2017.pdf

Shand, K. \& Farrelly, S. G. (2017). Using blended teaching to teach blended learning: Lessons learned from pre-service teachers in an instructional methods course. Journal of Online Learning Research, 3(1), 5-30. Retrieved from https://files.eric.ed.gov/fulltext/EJ1148421.pdf

Sifakis, N. C. (2014). ELF awareness as an opportunity for change: A transformative perspective for ESOL teacher education. Journal of English as a Lingua Franca, 3(2), 317-335. http://dx.doi.org/10.1515/ jelf-2014-0019

Sifakis, N. C. (2019). ELF awareness in English language teaching: Principles and processes. Applied Linguistics, 40(2), 288-306. https://doi.org/10.1093/applin/amx034

Sifakis, N. C. \& Bayyurt, Y. (2015). Insights from ELF and WE in teacher training in Greece and Turkey. World Englishes, 34(3), 471-484. https://doi.org/10.1111/weng.12150

Sifakis, N. C. \& Bayyurt, Y. (2018). ELF-aware teacher learning and development. In W. Baker, J. Jenkins \& M. Dewey (Eds.), Handbook of English as a Lingua Franca (pp. 456-467). New York: Routledge.

Stein, J. \& Graham, C. R. (2014). Essentials for blended learning: A standards-based guide. New York: Routledge.

Senturk, C. (2020). Effects of the blended learning model on preservice teachers' academic achievements and twenty-first century skills. Education and Information Technologies. https://doi.org/10.1007/ s10639-020-10340-y

Yilmaz, O. \& Malone, K. L. (2020). Preservice teachers' perceptions about the use of blended learning in a science education methods course. Smart Learning Environments, 7(18). https://doi.org/10.1186/ s40561-020-00126-7 